\title{
Epidermal growth factor receptor-tyrosine kinase inhibitors for non-small-cell lung cancer patients aged 80 years or older: A retrospective analysis
}

\author{
MAKOTO NAKAO $^{1}$, HIDEKI MURAMATSU ${ }^{1}$, KAZUKI SONE $^{1}$, SACHIKO AOKI $^{1}$, \\ HARATA AKIKO $^{2}$, YUSUKE KAGAWA ${ }^{1}$, HIDEFUMI SATO ${ }^{1}$ and TAKEFUMI KUNIEDA ${ }^{1}$ \\ ${ }^{1}$ Department of Respiratory Medicine, Kainan Hospital, Aichi Prefectural Welfare Federation of \\ Agricultural Cooperatives, Yatomi, Aichi 498-8502; ${ }^{2}$ Department of Respiratory Medicine, \\ Nagoya City East Medical Center, Nagoya, Aichi 464-8547, Japan
}

Received August 29, 2014; Accepted October 21, 2014

DOI: $10.3892 /$ mco.2014.453

\begin{abstract}
The efficacy of epidermal growth factor receptor-tyrosine kinase inhibitors (EGFR-TKIs) in elderly patients with non-small-cell lung cancer (NSCLC) remains uncertain. This retrospective study aimed to evaluate the efficacy and feasibility of EGFR-TKIs for NSCLC patients aged $\geq 80$ years. We analyzed data from 21 NSCLC patients aged $\geq 80$ years who were administered gefitinib and/or erlotinib between January, 2009 and December, 2014. The clinical characteristics, smoking status, type of EFGR mutation and the efficacy and toxicity of EGFR-TKIs were evaluated in these patients. In total, $14(66.7 \%), 5(23.8 \%)$ and 2 patients (9.5\%) displayed partial response, stable disease and progressive disease, respectively. The median progression-free survival was 182 days, whereas the median overall survival was 371 days. Adverse events $\geq$ grade 2 were as follows: skin toxicities, 12 patients; liver function test abnormalities, 7 patients; anorexia, 3 patients; and diarrhea, 2 patients. Dose reduction of EGFR-TKIs due to adverse events was required in 15 patients $(71.4 \%)$. Although gefitinib and erlotinib therapy may be beneficial in patients aged $\geq 80$ years, EGFR-TKI dose modification may be necessary according to the overall medical condition of elderly patients. Further studies are required to evaluate our findings.
\end{abstract}

\section{Introduction}

Lung cancer is one of the most common cancers worldwide, with non-small-cell lung cancer (NSCLC) accounting for

Correspondence to: Dr Makoto Nakao, Department of Respiratory Medicine, Kainan Hospital, Aichi Prefectural Welfare Federation of Agricultural Cooperatives, 396 Minamihonndenn, Maegasu-cho, Yatomi, Aichi 498-8502, Japan

E-mail: kokoro1979@gmail.com

Key words: extremely elderly patients, non-small-cell lung cancer, gefitinib, erlotinib $\sim 80 \%$ of the cases $(1,2)$. The risk of lung cancer clearly increases with advancing age and, with the prolongation of life expectancy, the number of elderly patients with lung cancer is expected to rapidly increase (3-5). According to the USA National Surveillance, Epidemiology and End Results database, approximately half of the patients with lung cancer were aged $\geq 70$ years. In addition, $14 \%$ of the patients with lung cancer were aged at least 80 years $(6,7)$. As a significant proportion of the NSCLC patients who are aged $\geq 80$ years present with advanced disease, a poor performance status (PS) at diagnosis and several comorbidities, there is a need for the development of suitable chemotherapy for such patients.

Recently, several reports described the safety and efficacy of gefitinib in patients with epidermal growth factor receptor $(E G F R)$ mutation-positive NSCLC aged $>70$ years and/or with a poor PS (2-4,7-9). The safety and efficacy of erlotinib in elderly patients with NSCLC were also reported $(10,11)$. Gefitinib and erlotinib are orally active EGFR-tyrosine kinase inhibitors (EGFR-TKIs), which have displayed notable efficacy in patients with advanced NSCLC $(2,12-14)$. Since the hematological toxicity of EGFR-TKIs is lower compared to that of cytotoxic chemotherapy, they may be of value as treatment for elderly patients and/or patients with poor PS.

However, the efficacy and toxicity of EGFR-TKIs in NSCLC patients aged $\geq 80$ years have not been fully evaluated. Whether standard anticancer therapy in extremely elderly patients with lung cancer is always safe in clinical practice remains unclear. In this study, we retrospectively assessed the value and safety of EGFR-TKIs in such patients.

\section{Patients and methods}

Patients. A total of 23 patients aged $\geq 80$ years with NSCLC were treated with EGFR-TKIs between January, 2009 and December, 2013 at Kainan Hospital (Yatomi, Aichi, Japan). Two patients were excluded from this analysis, as they were administered EGFR-TKIs for only a few days and data on treatment efficacy and toxicity were not available. Accordingly, a total of 21 patients were included in this analysis. The gefitinib group included patients who were treated with gefitinib alone 
or with gefitinib followed by erlotinib. The erlotinib group included patients treated with erlotinib alone or with erlotinib followed by gefitinib. In the gefitinib group, the patients were treated with oral gefitinib $250 \mathrm{mg}$ daily, $250 \mathrm{mg}$ every other day, or $250 \mathrm{mg}$ every 3 days. In the erlotinib group, the patients were treated with oral erlotinib 150,100 , or $50 \mathrm{mg}$ daily. The administration of EGFR-TKIs was continued until worsening of the general status, the development of unacceptable toxicity regardless of dose reduction, or the patients' refusal to continue treatment.

This study was approved by the Ethics committee of Kainan Hospital, Aichi Prefectural Welfare Federation of Agricultural Cooperatives. Written informed consent was obtained from all the patients prior to the initiation of EGFR-TKI treatment.

Patient characteristics and evaluation of response to treatment and toxicity. The patient characteristics, including the type of EGFR mutation, were retrospectively obtained from medical records. EGFR mutations were analyzed using the peptide nucleic acid-locked nucleic acid polymerase chain reaction clamp method (15) up to July, 2012. From August, 2012 onwards, EGFR exon 19 deletion was determined by fragment analysis and L858R point mutation was detected using the cycleave polymerase chain reaction technique (16). The patients were staged according to the 7th edition of the Union for International Cncer Control TNM classification prior to treatment initiation (17). The patients' adverse events, tolerance and response to treatment were retrospectively analyzed. Tumor response were classified as complete response (CR), partial response (PR), stable disease (SD) or progressive disease (PD), in accordance with the Response Evaluation Criteria for Solid tumors, version 1.1 (18). Toxicities were assessed according to the Common Terminology Criteria for Adverse Events, version 4.0 (http://ctep.cancer.gov/protocolDevelopment/electronic_applications/ctc.htm\#ctc_40)).

Statistical analysis. Progression-free survival (PFS) and overall survival (OS) rates were analyzed by the Kaplan-Meier method. PFS was measured from the date of initiation of gefitinib or erlotinib therapy to the date of progressive disease, death, or last follow-up. OS was defined as the time between the initiation of treatment and death or last follow-up. All the statistical analyses were performed with EZR statistical software (Saitama Medical Center, Jichi Medical University, Saitama, Japan), which is a graphical user interface for R (The $\mathrm{R}$ Foundation for Statistical Computing, Vienna, Austria). More precisely, EZR is a modified version of $\mathrm{R}$ commander designed to add statistical functions frequently used in biostatistics (19).

\section{Results}

Patient characteristics. The patients' characteristics are summarized in Table I. There were 8 male (38.1\%) and 13 female $(61.9 \%)$ patients, with a median age of 85 years (range, $80-96$ years). A total of 8 patients $(38.1 \%$ ) had an Eastern Cooperative Oncology Group PS of 2-3, whereas the remaining 13 patients had a PS of $0-1$. A total of 15 patients $(71.4 \%)$ were never smokers and $6(28.6 \%)$ were former smokers. Adenocarcinoma comprised the majority of the
Table I. Patient characteristics.

\begin{tabular}{|c|c|}
\hline Characteristics & $\begin{array}{l}\text { Patient no. } \\
\quad(n=21)\end{array}$ \\
\hline Age, years & $85(80-96)$ \\
\hline \multicolumn{2}{|l|}{ Median (range) } \\
\hline \multicolumn{2}{|l|}{ Sex } \\
\hline Male & 8 \\
\hline Female & 13 \\
\hline \multicolumn{2}{|l|}{ ECOG performance status } \\
\hline 0 & 4 \\
\hline 1 & 9 \\
\hline 2 & 5 \\
\hline 3 & 3 \\
\hline 4 & 0 \\
\hline \multicolumn{2}{|l|}{ Smoking status } \\
\hline Never & 15 \\
\hline Former & 6 \\
\hline Current & 0 \\
\hline \multicolumn{2}{|l|}{ Histology } \\
\hline Adenocarcinoma & 18 \\
\hline Squamous cell carcinoma & 2 \\
\hline Unknown & 1 \\
\hline \multicolumn{2}{|l|}{ Clinical stage at diagnosis } \\
\hline IIIA & 4 \\
\hline IIIB & 0 \\
\hline IV & 17 \\
\hline \multicolumn{2}{|l|}{ EGFR mutation } \\
\hline Exon 19 deletion & 5 \\
\hline L858R & 12 \\
\hline Negative & 3 \\
\hline Unknown & 1 \\
\hline \multicolumn{2}{|l|}{ Prior therapy } \\
\hline None & 16 \\
\hline Radiation & 2 \\
\hline Cytotoxic chemotherapy & 2 \\
\hline Surgery & 1 \\
\hline
\end{tabular}

ECOG, Eastern Cooperative Oncology Group; EGFR, epidermal growth factor receptor.

cancers (85.7\%). EGFR status was analyzed in 20 patients and EGFR mutations were identified in 17 patients (81\%). Of the 21 patients, $4(19 \%)$ had clinical stage IIIA disease at diagnosis, whereas the remaining $17(81 \%)$ had stage IV disease. A total of 5 patients received prior anticancer therapy; namely, 2 patients received cytotoxic chemotherapy (non-platinum-based chemotherapy), 2 patients received radiation therapy and 1 patient underwent surgery.

Patient EGFR status, treatment and outcomes. The characteristics and outcomes of the enrolled patients are listed in Table II. Of the 21 patients, 18 were administered gefitinib and 3 were administered erlotinib. As regards EGFR mutations, 
Table II. Patient characteristics and response to gefitinib or erlotinib therapy.

\begin{tabular}{|c|c|c|c|c|c|c|c|c|c|c|}
\hline $\begin{array}{l}\text { Case } \\
\text { no. }\end{array}$ & $\begin{array}{l}\text { Age } \\
\text { (yrs) }\end{array}$ & Gender & $\begin{array}{c}E G F R \\
\text { mutation }^{\mathrm{a}}\end{array}$ & $\begin{array}{c}\text { Type of } \\
\text { EGFR-TKI }\end{array}$ & $\begin{array}{c}\text { Dose } \\
\text { reduction }^{\mathrm{b}}\end{array}$ & Response & $\begin{array}{l}\text { Time to } \\
\text { progression } \\
\text { (days) }\end{array}$ & $\begin{array}{l}\text { Survival } \\
\text { (days) }\end{array}$ & $\begin{array}{c}\text { Subsequent } \\
\text { therapy }\end{array}$ & $\begin{array}{c}\text { Beyond } \\
\text { PD }^{c}\end{array}$ \\
\hline 1 & 85 & $\mathrm{~F}$ & L858R & Gefitinib & Yes & PR & 260 & 452 & None & Yes \\
\hline 2 & 85 & $\mathrm{~F}$ & Wild-type & Gefitinib & No & PD & 13 & 70 & None & No \\
\hline 3 & 82 & $\mathrm{~F}$ & L858R & Gefitinib & Yes & PR & 224 & 446 & None & Yes \\
\hline 4 & 81 & $\mathrm{~F}$ & L858R & Gefitinib & Yes & PR & 493 & 865 & Pemetrexed & No \\
\hline 5 & 86 & $\mathrm{~F}$ & Unkown & Gefitinib & Yes & PR & 159 & 192 & None & No \\
\hline 6 & 81 & $\mathrm{~F}$ & Exon 19 del & Gefitinib & Yes & PR & 223 & 371 & None & Yes \\
\hline 7 & 81 & M & L858R & Gefitinib & Yes & PR & 96 & 183 & None & Yes \\
\hline 8 & 85 & $\mathrm{~F}$ & Exon 19 del & Gefitinib & Yes & SD & 733 & 854 & None & Yes \\
\hline 9 & 88 & $\mathrm{~F}$ & L858R & Gefitinib & Yes & SD & 851 & 965 & None & No \\
\hline 10 & 83 & $\mathrm{~F}$ & Wild-type & Erlotinib & No & SD & 63 & 99 & None & No \\
\hline 11 & 81 & $\mathrm{~F}$ & Exon 19 del & Gefitinib & Yes & PR & 188 & 734 & Erlotinib & No \\
\hline 12 & 96 & $\mathrm{M}$ & L858R & Erlotinib & Yes & PR & 84 & 107 & None & No \\
\hline 13 & 86 & $\mathrm{~F}$ & L858R & Gefitinib & Yes & PR & 272 & 710 & None & Yes \\
\hline 14 & 81 & $\mathrm{M}$ & L858R & Gefitinib & No & SD & 554 & 661 & None & No \\
\hline 15 & 83 & $\mathrm{~F}$ & L858R & Gefitinib & Yes & PR & 112 & 580 & Erlotinib & No \\
\hline 16 & 80 & M & Wild-type & Erlotinib & Yes & SD & 55 & 361 & Radiation & No \\
\hline 17 & 85 & $\mathrm{M}$ & Exon 19 del & Gefitinib & No & PD & 12 & 12 & None & No \\
\hline 18 & 85 & M & L858R & Gefitinib & No & PR & 66 & 172 & Erlotinib & No \\
\hline 19 & 90 & $\mathrm{M}$ & Exon 19 del & Gefitinib & Yes & PR & 166 & 341 & Erlotinib & Yes \\
\hline 20 & 80 & $\mathrm{M}$ & L858R & Gefitinib & Yes & PR & 182 & 221 & None & No \\
\hline 21 & 89 & $\mathrm{~F}$ & L858R & Gefitinib & No & PR & 273 & 273 & None & No \\
\hline
\end{tabular}

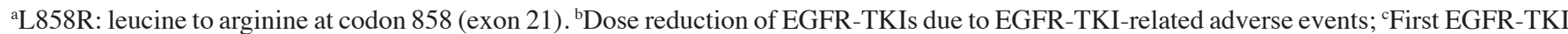
therapy beyond disease progression. M, male; F, female; PR, partial response; SD, stable disease; PD, progressive disease; EGFR, epidermal growth factor receptor; TKI, tyrosine kinase inhibitor.

12 patients carried the L858R mutation in exon 21 and 5 carried deletions in exon 19. The median treatment duration was 197 days (range, 12-965 days). No patients achieved CR, whereas 14 patients $(66.7 \%)$ achieved PR. The disease control rate, defined as the percentage of patients who achieved CR, PR, or SD, was 90.5\%. Dose reduction of EGFR-TKIs due to adverse events was required in 15 patients $(71.4 \%)$. A total of 7 patients $(33.3 \%$ ) continued with the EGFR-TKI therapy beyond PD. In the gefitinib group, 4 patients received subsequent erlotinib therapy following termination of gefitinib therapy. The average follow-up duration was 413 days (range, 12-965 days). The median PFS was 182 days (Fig. 1) and the median OS was 371 days (Fig. 2). Of the 17 patients harboring EGFR mutations, 13 (76.5\%) achieved PR and the median PFS and OS were 223 and 452 days, respectively.

Adverse events. The treatment-related adverse events are summarized in Table III. The most common adverse event associated with EGFR-TKIs was skin toxicities (57.1\%). Skin toxicities $\geq$ grade 2 were as follows: skin rash, 9 patients (42.9\%); dry skin, 6 patients; $(28.6 \%)$; pruritus, 5 patients (23.8\%); and paronychia, 3 patients (14.3\%). Liver function test abnormalities $\geq$ grade 2 were observed in 7 patients $(33.3 \%)$. Other adverse events $\geq$ grade 2 were as follows: anorexia,

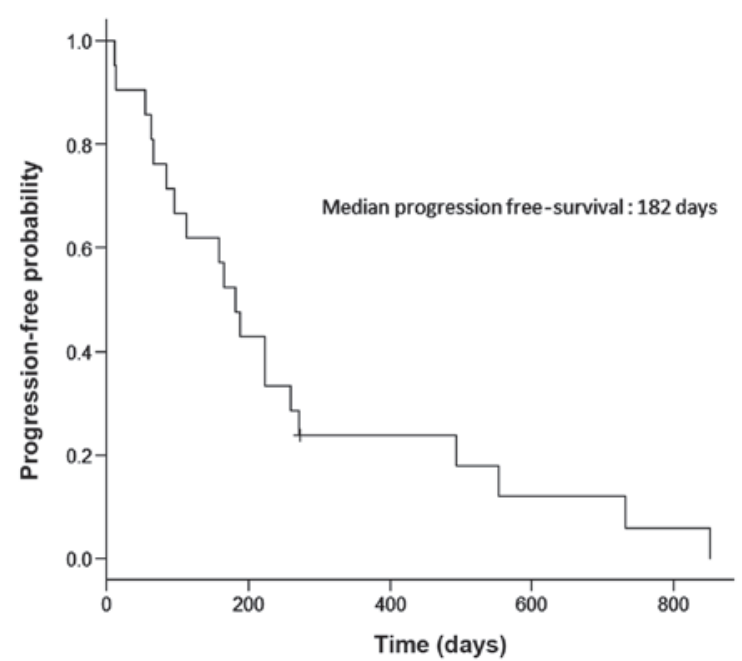

Figure 1. Kaplan-Meier curve for progression-free survival in the 21 patients treated with epidermal growth factor receptor-tyrosine kinase inhibitors. Median progression-free survival, 182 days.

3 patients (14.3\%); diarrhea, 2 patients $(9.5 \%)$; general fatigue, 2 patients $(9.5 \%)$; and anemia, leukopenia, elevated amylase and nausea, 1 patient each $(4.8 \%)$. Adverse events $\geq$ grade 4 or interstitial lung disease (ILD) were not observed in this study. 
Table III. Adverse events.

\begin{tabular}{|c|c|c|c|c|c|c|}
\hline \multirow[b]{2}{*}{ Toxicity } & \multicolumn{4}{|c|}{ Grade, no. } & \multirow[b]{2}{*}{$\geq$ Grade 1 , no. $(\%)$} & \multirow[b]{2}{*}{$\geq$ Grade 2 , no. $(\%)$} \\
\hline & 1 & 2 & 3 & 4 & & \\
\hline Skin rash & 5 & 4 & 5 & 0 & $14(66.7)$ & $9(42.9)$ \\
\hline Dry skin & 3 & 4 & 2 & 0 & $9(42.9)$ & $6(28.6)$ \\
\hline Pruritus & 1 & 3 & 2 & 0 & $6(28.6)$ & $5(23.8)$ \\
\hline Paronychia & 1 & 3 & 0 & 0 & $4(19.0)$ & $3(14.3)$ \\
\hline Diarrhea & 7 & 2 & 0 & 0 & $9(42.9)$ & $2(9.5)$ \\
\hline Nausea & 2 & 1 & 0 & 0 & $3(14.3)$ & $1(4.8)$ \\
\hline Vomiting & 2 & 0 & 0 & 0 & $2(9.5)$ & $0(0.0)$ \\
\hline Anorexia & 3 & 2 & 1 & 0 & $6(28.6)$ & $3(14.3)$ \\
\hline Stomatitis & 3 & 0 & 0 & 0 & $3(14.3)$ & $0(0.0)$ \\
\hline Dysgeusia & 2 & 0 & 0 & 0 & $2(9.5)$ & $0(0.0)$ \\
\hline Dry mouth & 1 & 0 & 0 & 0 & $1(4.8)$ & $0(0.0)$ \\
\hline Elevated AST/ALT/ALP & 4 & 4 & 3 & 0 & $11(52.4)$ & $7(33.3)$ \\
\hline Elevated amylase & 0 & 0 & 1 & 0 & $1(4.8)$ & $1(4.8)$ \\
\hline Interstitial lung disease & 0 & 0 & 0 & 0 & $0(0.0)$ & $0(0.0)$ \\
\hline Leukopenia & 1 & 1 & 0 & 0 & $2(9.5)$ & $1(4.8)$ \\
\hline Anemia & 0 & 1 & 0 & 0 & $1(4.8)$ & $1(4.8)$ \\
\hline Thrombocytopenia & 0 & 0 & 0 & 0 & $0(0.0)$ & $0(0.0)$ \\
\hline Epistaxis & 2 & 0 & 0 & 0 & $2(9.5)$ & $0(0.0)$ \\
\hline Increased creatinine & 1 & 0 & 0 & 0 & $1(4.8)$ & $0(0.0)$ \\
\hline General fatigue & 1 & 2 & 0 & 0 & $3(14.3)$ & $2(9.5)$ \\
\hline Leg edema & 1 & 0 & 0 & 0 & $1(4.8)$ & $0(0.0)$ \\
\hline
\end{tabular}

AST, aspartate aminotransferase; ALT, alanine aminotransferase; ALP, alkaline phosphatase.

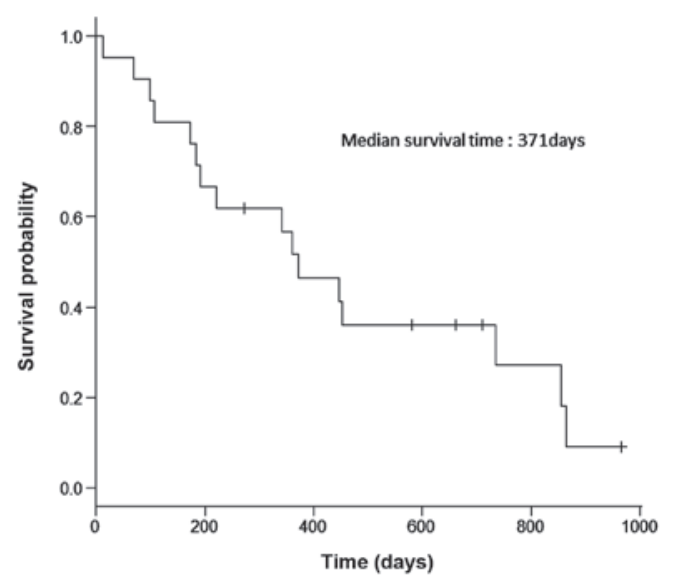

Figure 2. Kaplan-Meier curve for overall survival in the 21 patients treated with epidermal growth factor receptor-tyrosine kinase inhibitors. Median survival time, 371 days.

\section{Discussion}

Gefitinib and erlotinib have displayed acceptable efficacy in NSCLC patients aged $\geq 80$ years. However, a dose reduction of EGFR-TKIs due to adverse events were required in $>70 \%$ of our study subjects. To the best of our knowledge, this is the first study targeting extremely elderly patients with NSCLC who were treated with EGFR-TKIs.
Several recent studies described the efficacy of gefitinib and erlotinib for elderly patients with $\operatorname{NSCLC}(3,4,7-11,20,21)$. In studies of elderly patients not selected by EGFR mutation status, the overall response rates (RRs) were $10-25 \%$, the median PFS was 2.7-4 months and the median OS was 7.6-11.9 months $(4,7,10,11,20)$. By contrast, in studies of $E G F R$ mutation-positive elderly patients, the overall RRs were 59-74\%, the median PFS was 12.3-13.8 months and the median OS was 17.4-29.1 months $(3,8,9,21)$. In our study, the overall RR was $66.7 \%$, the median PFS was 6.1 months and the median OS was 12.4 months. A total of 17 patients $(81 \%)$ had sensitive EGFR mutations in this study and, among these patients, PR was observed in $76.5 \%$ of patients and the median PFS and OS were 7.4 and 15.1 months, respectively. The high prevalence of EGFR mutation is considered to reflect that mutation-positive patients are more likely to receive gefitinib or erlotinib therapy compared to EGFR mutation-negative patients. As regards the efficacy of EGFR-TKI therapy, considering the age of our study population, the results of our study may be considered acceptable in comparison to those of previous studies.

Elderly patients with lung cancer prefer to receive less toxic anticancer chemotherapy (7). Such patients generally present with more comorbidities and more compromised organ functions compared to younger patients; even elderly patients with a good PS may be at higher risk of severe toxicity compared to younger patients $(3,22)$. A subgroup analysis of the BR.21 study revealed that elderly patients with NSCLC who were 
treated with erlotinib displayed similar efficacy as younger patients, but experienced more significant toxicity $(3,23)$. In addition, advanced age has been reported to be a risk factor for ILD in Japanese subjects during gefitinib treatment (24). Therefore, extremely elderly patients who were treated with EGFR-TKIs should be carefully monitored for adverse events. In previous studies, dose reduction or discontinuation of EGFR-TKIs due to adverse events was observed in 19-51.5\% of the patients $(3,7,10,11,25,26)$, whereas in our study, $76.1 \%$ of the patients required dose reduction or discontinuation (dose reduction in 15 patients and treatment discontinuation in 1 patient, due to liver function test abnormalities). There were no fatal toxicities, including ILD, whereas almost all types of toxicity were manageable by dose modification in both EGFR-TKI groups. Satoh et al (25) reported that low-dose gefitinib was clinically comparable to standard-dose gefitinib for NSCLC in patients with sensitive EGFR mutations. Therefore, we may be able to suggest that reduced-dose gefitinib and erlotinib therapy may be suitable for extremely elderly patients.

The limitations of our study were the small sample size, retrospective nature, heterogeneity of the treatment regimens and being a single-arm study. As our study was based on clinical data from a small sample of patients in a single facility, larger prospective trials on patients aged $\geq 80$ years treated with EGFR-TKIs should be conducted to reveal the true efficacy and toxicity of this treatment. In addition, as Togashi et al reported that $150 \mathrm{mg}$ erlotinib daily was associated with more toxicity and less tolerability compared to $250 \mathrm{mg}$ gefitinib daily (12), an independent research program regarding gefitinib and erlotinib therapy should be conducted.

In conclusion, reduced-dose gefitinib or erlotinib therapy may be an effective and tolerable regimen for NSCLC patients aged $\geq 80$ years, particularly those with EGFR mutations. The information presented in our study may provide some directions for clinical research on the treatment of such patients. However, further large studies are required to validate our findings.

\section{References}

1. Parkin DM: Global cancer statistics in the year 2000. Lancet Oncol 2: 533-543, 2001

2. Inoue A, Kobayashi K, Usui K, et al: First-line gefitinib for patients with advanced non-small-cell lung cancer harboring epidermal growth factor receptor mutations without indication for chemotherapy. J Clin Oncol 27: 1394-1400, 2009.

3. Maemondo M, Minegishi Y, Inoue A, et al: First-line gefitinib in patients aged 75 or older with advanced non-small cell lung cancer harboring epidermal growth factor receptor mutations: NEJ 003 study. J Thorac Oncol 7: 1417-1422, 2012.

4. Hotta K, Ueoka H, Kiura K, et al: Safety and efficacy of gefitinib treatment in elderly patients with non-small-cell lung cancer: Okayama Lung Cancer Study Group experience. Acta Oncol 44 717-722, 2005.

5. Bunn PA Jr and Lilenbaum R: Chemotherapy for elderly patients with advanced non-small-cell lung cancer. J Natl Cancer Inst 95: 341-343, 2003

6. Owonikoko TK, Ragin CC, Belani CP, et al: Lung cancer in elderly patients: an analysis of the surveillance, epidemiology, and end results database. J Clin Oncol 25: 5570-5577, 2007.

7. Kobayashi M, Matsui K, Katakami N, et al; West Japan Oncology Group: Phase II study of gefitinib as a first-line therapy in elderly patients with pulmonary adenocarcinoma: West Japan thoracic oncology group study 0402. Jpn J Clin Oncol 41: 948-952, 2011.

8. Uruga H, Kishi K, Fujii T, et al: Efficacy of gefitinib for elderly patients with advanced non-small cell lung cancer harboring epidermal growth factor receptor gene mutations: a retrospective analysis. Intern Med 49: 103-107, 2010.
9. Asami K, Koizumi T, Hirai K, et al: Gefitinib as first-line treatment in elderly epidermal growth factor receptor-mutated patients with advanced lung adenocarcinoma: results of a Nagano Lung Cancer Research Group study. Clin Lung Cancer 12: 387-392, 2011.

10. Rossi D, Dennetta D, Ugolini M, et al: Activity and safety of erlotinib as second- and third-line treatment in elderly patients with advanced non-small cell lung cancer: a phase II trial. Target Oncol 5: 231-235, 2010

11. Jackman DM, Yeap BY, Lindeman NI, et al: Phase II clinical trial of chemotherapy-naive patients $>$ or $=70$ years of age treated with erlotinib for advanced non-small-cell lung cancer. J Clin Oncol 25: 760-766, 2007.

12. Togashi Y, Masago K, Fujita S, et al: Differences in adverse events between $250 \mathrm{mg}$ daily gefitinib and $150 \mathrm{mg}$ daily erlotinib in Japanese patients with non-small cell lung cancer. Lung Cancer 74: 98-102, 2011

13. Shepherd FA, Rodrigues Pereira J, Ciuleanu T, et al: Erlotinib in previously treated non-small-cell lung cancer. N Engl J Med 353: $123-132,2005$.

14. Fukuoka M, Yano S, Giaccone G, et al: Multi-institutional randomized phase II trial of gefitinib for previously treated patients with advanced non-small-cell lung cancer (The IDEAL 1 Trial) [corrected]. J Clin Oncol 21: 2237-2246, 2003.

15. Nagai Y, Miyazawa H, Huqun, et al: Genetic heterogeneity of the epidermal growth factor receptor in non-small cell lung cancer cell lines revealed by a rapid and sensitive detection system, the peptide nucleic acid-locked nucleic acid PCR clamp. Cancer Res 65: 7276-7282, 2005

16. Yoshida K, Yatabe Y, Park JY, et al: Prospective validation for prediction of gefitinib sensitivity by epidermal growth factor receptor gene mutation in patients with non-small cell lung cancer. J Thorac Oncol 2: 22-28, 2007.

17. Goldstraw P, Crowley J, Chansky K, et al; International Association for the Study of Lung Cancer International Staging Committee; Participating Institutions: The IASLC Lung Cancer Staging Project: proposals for the revision of the TNM stage groupings in the forthcoming (seventh) edition of the TNM Classification of malignant tumours. J Thorac Oncol 2: 706-714, 2007.

18. Eisenhauer EA1, Therasse P, Bogaerts J, et al: New response evaluation criteria in solid tumours: revised RECIST guideline (version 1.1). Eur J Cancer 45: 228-247, 2009.

19. Kanda Y: Investigation of the freely available easy-to-use software 'EZR' for medical statistics. Bone Marrow Transplant 48: 452-458, 2013.

20. Ebi N, Semba H, Tokunaga SJ, et al: A phase II trial of gefitinib monotherapy in chemotherapy-naive patients of 75 years or older with advanced non-small cell lung cancer. J Thorac Oncol 3: 1166-1171, 2008

21. Tateishi K, Ichiyama T, Hirai K, et al: Clinical outcomes in elderly patients administered gefitinib as first-line treatment in epidermal growth factor receptor-mutated non-small-cell lung cancer: retrospective analysis in a Nagano Lung Cancer Research Group study. Med Oncol 30: 450, 2013.

22. Chrischilles EA, Pendergast JF, Kahn KL, et al: Adverse events among the elderly receiving chemotherapy for advanced non-small-cell lung cancer. J Clin Oncol 28: 620-627, 2010.

23. Wheatley-Price P, Ding K, Seymour L, Clark GM and Shepherd FA: Erlotinib for advanced non-small-cell lung cancer in the elderly: an analysis of the National Cancer Institute of Canada Clinical Trials Group study BR.21. J Clin Oncol 26: 2350-2357, 2008

24. Kudoh S, Kato H, Nishiwaki Y, et al: Interstitial lung disease in Japanese patients with lung cancer: a cohort and nested case-control study. Am J Respir Crit Care Med 177: 1348-1357, 2008.

25. Satoh H, Inoue A, Kobayashi K, et al: Low-dose gefitinib treatment for patients with advanced non-small cell lung cancer harboring sensitive epidermal growth factor receptor mutations. J Thorac Oncol 6: 1413-1417, 2011.

26. Goto K, Nishio M, Yamamoto N, et al: A prospective, phase II, open-label study (JO22903) of first-line erlotinib in Japanese patients with epidermal growth factor receptor (EGFR) mutation-positive advanced non-small-cell lung cancer (NSCLC). Lung Cancer 82: 109-114, 2013. 